\title{
Combustion of Laser-Induced Individual Magnesium Microparticles under Natural Convection
}

\author{
Chengyuan Lin ${ }^{1}$, Minqi Zhang ${ }^{1}$, Yue Wang ${ }^{1}$, Shengji Li ${ }^{2, * \mathbb{D}}$, Xuefeng Huang ${ }^{1, * \mathbb{D}}$, Jiangrong Xu ${ }^{1}$ \\ and Sunqiang $\operatorname{Pan}^{3}$ (D)
}

1 Institute of Energy, Department of Physics, Hangzhou Dianzi University, Hangzhou 310018, China; linchengyuan@hdu.edu.cn (C.L.); 191070067@hdu.edu.cn (M.Z.); coldfire1@163.com (Y.W.); jrxu@hdu.edu.cn (J.X.)

2 College of Materials and Environmental Engineering, Hangzhou Dianzi University, Hangzhou 310018, China

3 Division of Biological and Chemical Metrology, Zhejiang Institute of Metrology, Hangzhou 310018, China; pansunqiang@hotmail.com

* Correspondence: shengjili@hdu.edu.cn (S.L.); xuefenghuang@hdu.edu.cn (X.H.); Tel.: +86-571-8687-8677 (X.H.)

check for updates

Citation: Lin, C.; Zhang, M.; Wang, Y.; Li, S.; Huang, X.; Xu, J.; Pan, S. Combustion of Laser-Induced Individual Magnesium Microparticles under Natural Convection. Processes 2021, 9, 1276. https://doi.org/ $10.3390 /$ pr9081276

Academic Editor: Zhihua Wang

Received: 17 June 2021

Accepted: 21 July 2021

Published: 24 July 2021

Publisher's Note: MDPI stays neutral with regard to jurisdictional claims in published maps and institutional affiliations.

Copyright: (c) 2021 by the authors. Licensee MDPI, Basel, Switzerland. This article is an open access article distributed under the terms and conditions of the Creative Commons Attribution (CC BY) license (https:/ / creativecommons.org/licenses/by/ $4.0 /)$.
Abstract: Metal magnesium (Mg) fuels have been widely used in rocket propellants. The combustion study on individual $\mathrm{Mg}$ microparticles is crucial to the in-depth unveiling of the combustion mechanism of $\mathrm{Mg}$-based propellants. In this paper, a new experimental setup was proposed to directly observe the combustion of individual micron-sized $\mathrm{Mg}$ particles, based on laser ignition and microscopic high-speed cinematography. The combustion process of individual $\mathrm{Mg}$ microparticles could be directly and clearly observed by the apparatus at high temporal and spatial resolutions. Individual $\mathrm{Mg}$ microparticles took gas phase combustion, and mainly underwent four stages: expansion, melting, gasification, ignition, and combustion. The ignition delay time and total combustion time had an exponential decay on the particle diameter, and they had a linear decay on the ignition power density. The melting took a dominant role in the whole burnout time. The gas-phase combustion flame seemed thick, inhomogeneous, and ring-like structure. The combustion model of individual Mg microparticles was built through combining the experimental results with the SEM, XRD, XPS, and EDS analysis of original samples and combustion residues. This study will be beneficial to understand the combustion process and reveal the combustion mechanism of metal microparticles besides $\mathrm{Mg}$.

Keywords: metal fuels; magnesium (Mg); individual microparticles; laser ignition; microscopic high-speed cinematography

\section{Introduction}

Compared to metals like aluminum and boron, magnesium (Mg) has the advantages of lower ignition temperature, shorter burn time, smaller molecular weight of combustion products [1-3], and lower oxygen consumption, which can burn completely at low oxygen fuel ratio in ramjet flying at high altitude [4]. Therefore, much more attention has been paid to the research of $\mathrm{Mg}$-based propellants. The combustion of $\mathrm{Mg}$ particles in air is not only used in conventional ramjet engines, but also widely used in powdered fuel ramjets. In the conventional ramjet, the reaction of metal particles with the air produces high temperature gas, the high temperature gas then enters the secondary combustion chamber to drive the ramjet [5]. However, in a powdered fuel ramjet, the high-energy metal powder can directly enter the precombustion chamber in the form of two-phase flow under the action of fluidized gas and react with the ram air [6]. Therefore, it is of great significance to study the ignition and combustion of $\mathrm{Mg}$ particles in air, to further reveal the combustion mechanism of solid rocket propellant and applied in powdered fuel ramjet.

The performance of propellants largely depends on the combustion details of metal particles, including deformation, accumulation, ignition, and diffusion of combustion 
products, etc. Many experiments and theoretical studies have been carried out to unveil the combustion behavior of $\mathrm{Mg}$ in different ambiences. In the early 1960s, Cassel [7] carried out the experiment on the combustion of $\mathrm{Mg}$ particles with diameters of 20-120 $\mu \mathrm{m}$ in air or pure $\mathrm{O}_{2}$. It was considered that the combustion of $\mathrm{Mg}$ particles in air was controlled by the diffusion rate of $\mathrm{O}_{2}$. Prachukho et al. [8] studied the combustion characteristics of single micron-sized $\mathrm{Mg}$ particles in high temperature steam, which observed that $\mathrm{Mg}$ particles took gas phase combustion. Later, Derevyaga [9] studied the combustion mechanism of large $\mathrm{Mg}$ particles with diameters of 3,4, and $6 \mathrm{~mm}$ in high temperature $\mathrm{O}_{2}$. The combustion of $\mathrm{Mg}$ in $\mathrm{O}_{2}$ could be divided into four stages: foam stage, gaseous oxidation stage, transition stage, and sputtering combustion stage. Shafirovich and Goldshleger $[10,11]$ investigated the ignition and combustion characteristics of $\mathrm{Mg}$ particles in $\mathrm{CO}_{2} / \mathrm{CO}$ in a high temperature furnace. It was found that the soot formed on the surface of $\mathrm{Mg}$ particles during ignition and combustion in $\mathrm{CO}_{2}$. During ignition, the particles gradually melted and volatilized as the temperature elevated. When the temperature rose to a certain extent, the protective oxide film broke down, and then the particle took the gaseous combustion.

The combustion characteristics of $\mathrm{Mg}$ particles depend on not only the ambiences but also their physicochemical properties. Yuan et al. [12] conducted the thermal analysis on the reaction of $\mathrm{Mg}$ with nitrogen and oxygen mixture, which studied the reaction characteristics of $\mathrm{Mg}$ powder under different nitrogen concentration by thermogravimetric analysis (TGA) method. The activation energy of $\mathrm{Mg}$ powder oxidation in air by the Kissinger-Akahira-Sunose (KAS) method was $234 \mathrm{~kJ} / \mathrm{mol}$. The activation energy related to the properties of corresponding protective film at the particle surface.

To further reveal the combustion behavior of individual Mg particles, Legrand et al. [13] studied the ignition and combustion performance of $\mathrm{Mg}$ particles levitated by an electrodynamic levitator in $\mathrm{CO}_{2}$ gas. The results showed that the combustion of $\mathrm{Mg}$ particles in $\mathrm{CO}_{2}$ consisted of two chemical reaction processes, i.e., gaseous combustion and heterogeneous reaction at the particle surface, but the whole combustion process of vapor phase was controlled by the diffusion rate.

In this work, we proposed a novel experimental apparatus to directly observe the ignition and combustion process of individual $\mathrm{Mg}$ microparticles by combining laser ignition and microscopic high-speed cinematography, like thermal expansion, melting, gasification, and heterogeneous combustion. The apparatus was simplified by optimizing optical design and integrating optical components, which can acquire the images of combustion at high temporal and spatial resolutions. Firstly, the physical parameters of $\mathrm{Mg}$ microparticles were characterized by multiple methodology of SEM, XRD, XPS, and EDS, etc. Secondly, the ignition and combustion characteristics were elaborately demonstrated based on the self-built experimental setup. The effects of particle diameter and ignition power density on the ignition and combustion characteristics were summarized. The combustion residues were characterized by SEM and EDS. Finally, the simple physical model of individual $\mathrm{Mg}$ microparticle combustion was built according to the experimental phenomena and theoretical analysis.

\section{Materials and Methods}

\subsection{Materials}

The Mg microparticles were prepared by melt atomization technique presented in our previous work [14]. The morphology of as-prepared $\mathrm{Mg}$ microparticles was characterized by SEM (Quanta 600FEG, Thermo Fisher Scientific, Waltham, MA, USA), as shown in Figure 1. $\mathrm{Mg}$ microparticles are spherical, there are a few cracks of reticular structure at the particle surface. According to PillingBedworth theory, the dense oxide film will form when the volume ratio of metal oxide to metal atom (Pilling-Bedworth ratio, RPB) is $>1$. The RPB of Mg is of 0.8 , thus the oxide film is not compact but porous [15], which is consistent with the present SEM results. Additionally, no significant agglomeration among $\mathrm{Mg}$ microparticles was observed. While it can be observed that few finer particles adhered 
on the surface of large particles, which attributed to the satellite drops produced during melt atomization.

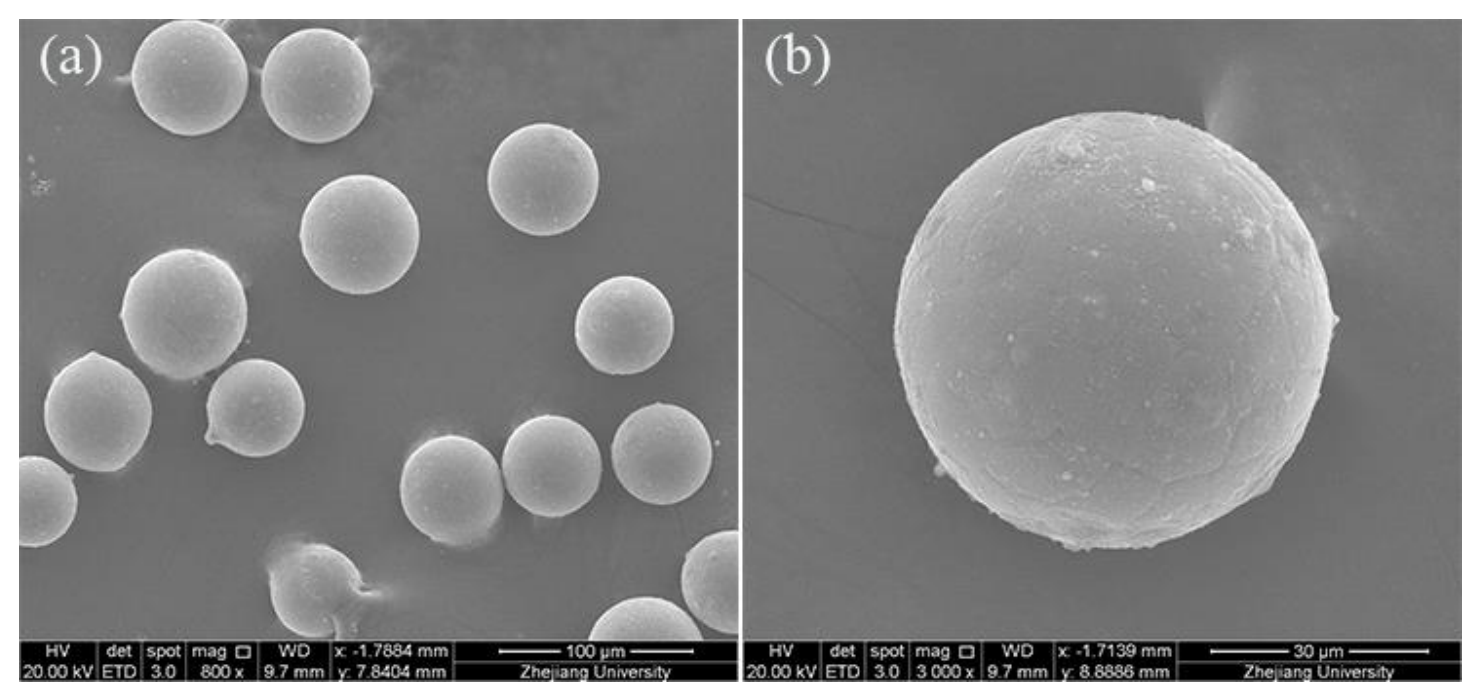

Figure 1. SEM photography of Mg microparticles, (a) $800 \times$, (b) $3000 \times$.

The XRD pattern of Mg microparticles was obtained by an Empyrean X-ray diffractometer (Malvern Panalytical Ltd., Malvern, UK) under Cu Ka radiation of 16 kW, as shown in Figure 2. In total, 8 characteristic diffraction peaks are at $2 \theta$ (marked as filled circles in Figure 2) about $32.20^{\circ}, 34.40^{\circ}, 36.63^{\circ}, 47.83^{\circ}, 57.38^{\circ}, 63.06^{\circ}, 68.64^{\circ}$, and $70.00^{\circ}$, which are in accordance with the diffraction peaks of $\mathrm{Mg}$ particles.

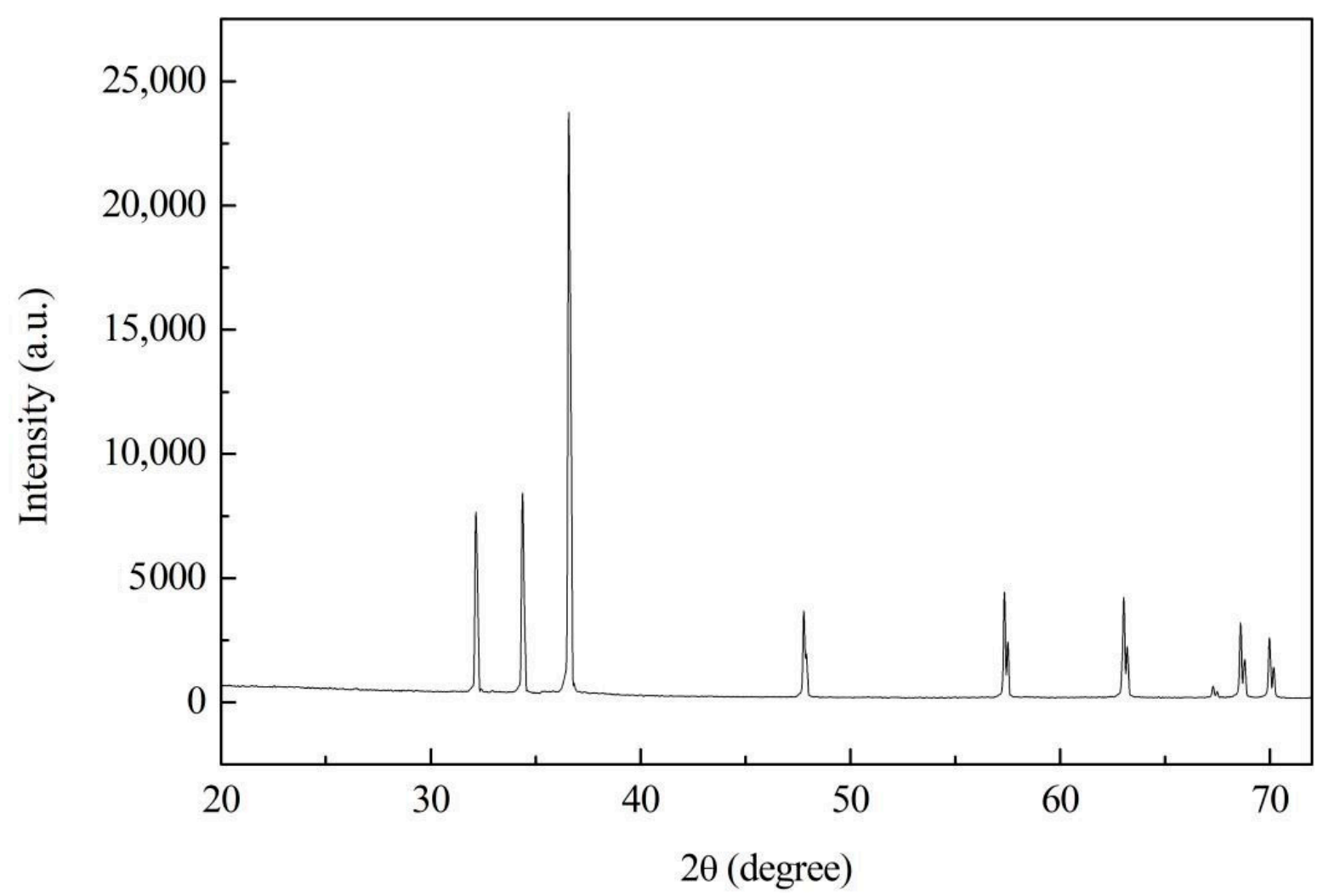

Figure 2. XRD pattern of Mg microparticles. 
The as-prepared Mg microparticles were further characterized by XPS, the spectrum is shown in Figure 3. At the $\mathrm{Mg}$ particle surface, $\mathrm{Mg}$ and $\mathrm{O}$ elements were observed, suggesting that the surface of $\mathrm{Mg}$ microparticle was covered with the magnesium oxide or possible magnesium hydroxide. It concluded that the oxide shell outside of $\mathrm{Mg}$ microparticle was not compact according to Figures 1 and 3, unlike the compact alumina shell outside metallic aluminum.

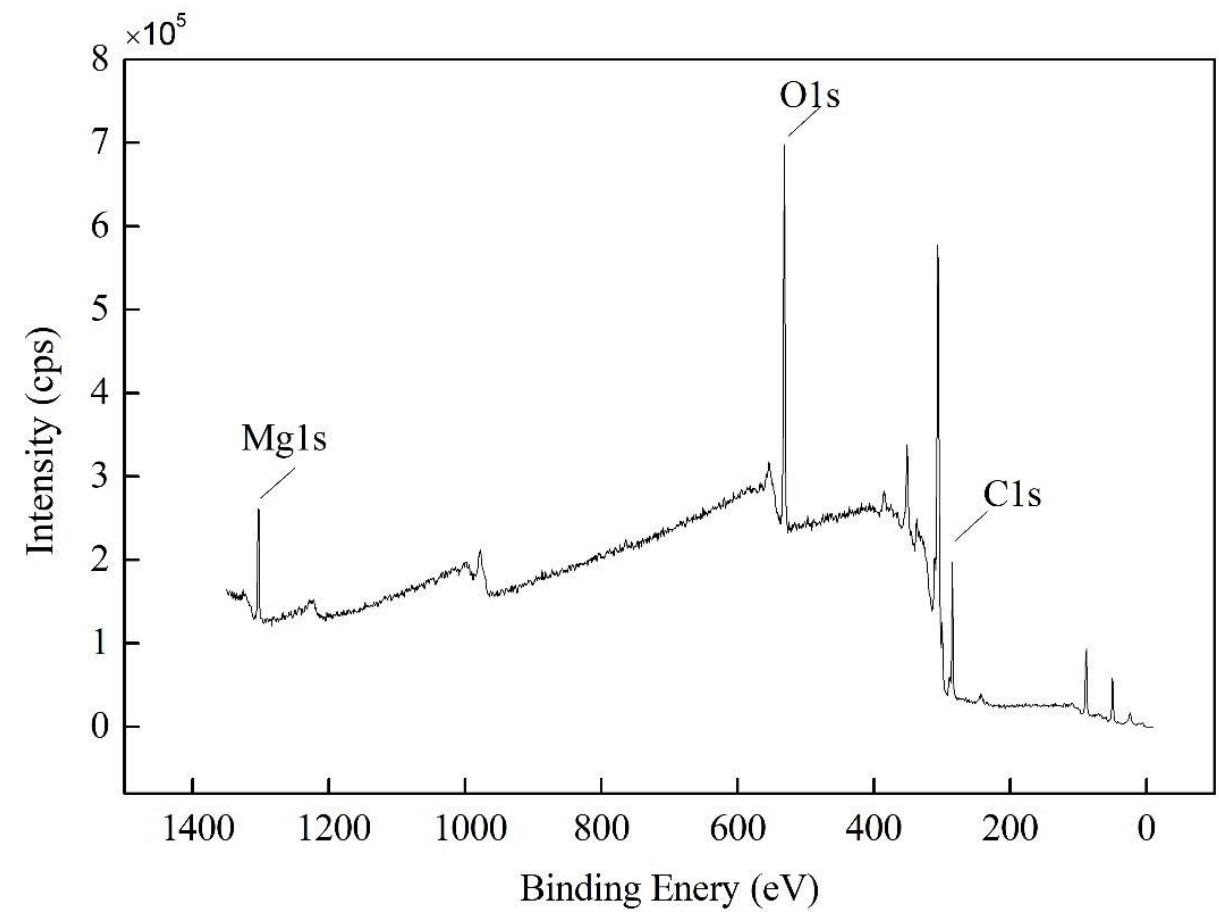

Figure 3. XPS spectrum of Mg microparticles.

The physical depth of interaction $(<10 \mathrm{~nm})$ of XPS analysis is less than the thickness of magnesium oxide film. Thus, to obtain the purity of $\mathrm{Mg}$ microparticles, the EDS analysis (depth of interaction $>1 \mu \mathrm{m}$, INCA Energy 300, Oxford Instruments, Oxford, UK) was conducted. The position of interaction and corresponding spectrum are shown in Figure 4. It demonstrates that the purity of the $\mathrm{Mg}$ microparticle was $\sim 100 \%$, and the oxidation only occurred at the particle surface.
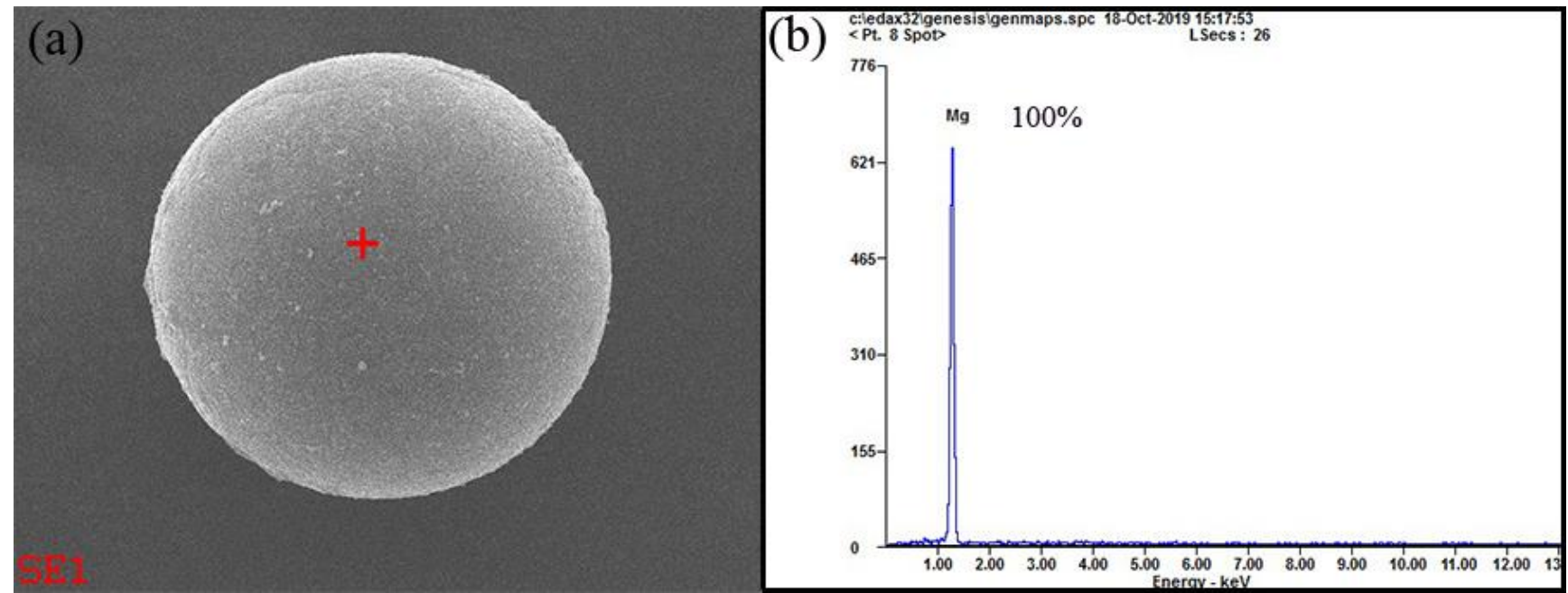

Figure 4. EDS spectrum of Mg microparticles, (a) probing position marked as “+”, (b) EDS spectrum. 


\subsection{Experimental Setup}

\subsubsection{Laser Ignition}

The schematic of experimental setup is shown in Figure 5, including laser ignition and microscopic high-speed cinematography parts. A continuous wave $\mathrm{Nd}$ : $\mathrm{YVO}_{4}$ nearinfrared laser (wavelength of $1064 \mathrm{~nm}, \mathrm{TEM}_{00}$ mode, beam divergence of $1.5 \mathrm{mrad}$ (full angle) and variable output power of $0-600 \mathrm{~mW}$ ) was used to ignite individual $\mathrm{Mg} \mathrm{mi-}$ croparticles. The laser beam is first split into two beams by the splitter (1:9). The dominant forward beam transmits through the beam expander $(3 \times)$ and the dichroic to the objective. The weak beam enters the probing of power meter to measure the laser power. The objective (Olympus Plan N 20×, NA of 0.40) focuses the beam to ignite Mg microparticles. The laser was continuously powered on throughout the test of each $\mathrm{Mg}$ microparticle. The beam power acted on the microparticles $\left(P_{\mathrm{L}}\right)$ was reduced by $\sim 50 \%$ of laser output power owing to the attenuation of the lens and objective in the optical system. The laser beam spot profile was acquired by the high-speed camera, and the waist diameter of focused beam spot $\left(D_{\mathrm{fbs}}\right)$ could be measured by Gaussian fitting. The diameter of beam spot is $13.9 \mu \mathrm{m}$, less than those of $\mathrm{Mg}$ microparticles. Therefore, the ignition power density (IPD) can be expressed by the ratio of the beam power to the area of focal spot $\left(I P D=4 P_{\mathrm{L}} /\left(\pi D^{2} \mathrm{fbs}\right)\right)$. More details about the setup could be found in our previous work [16].

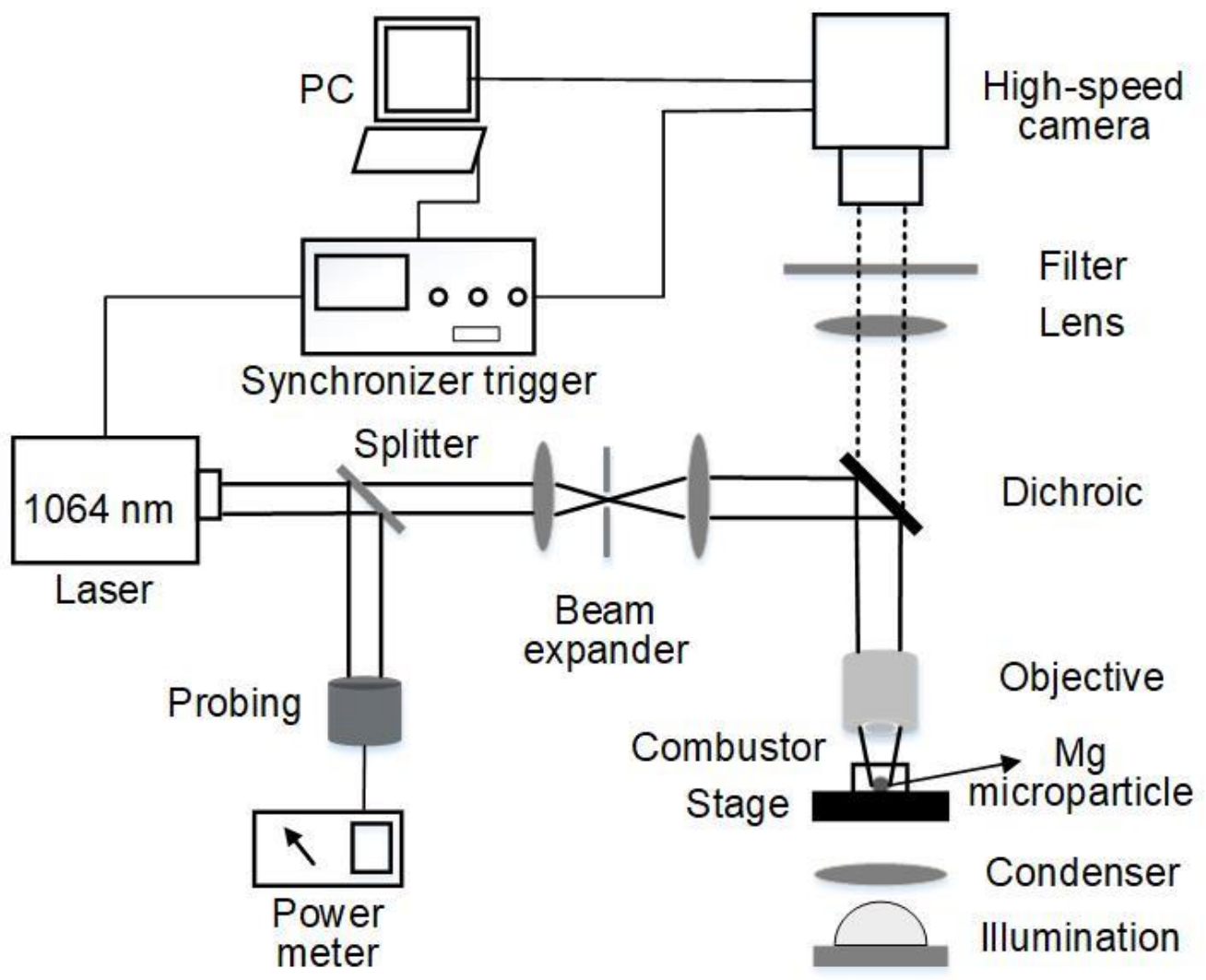

Figure 5. Schematic of experimental setup.

\subsubsection{Microscopic High-Speed Cinematography}

Microscopic high-speed cinematography part was composed of high-speed camera, filter, lens, dichroic, objective, illumination, and condenser. An individual Mg microparticle was magnified by the objective $(20 \times)$. High-speed camera (Phantom Micro M310, Vision Research Inc., Wayne, NJ, USA) was utilized to record the combustion process. A lens was installed in front of high-speed camera. The notch filter of $1064 \mathrm{~nm}$ was inserted to minimize the influence of laser beam on the flame images. The illumination (LED lamp) and the condenser were used to supply uniform bright field for clear imaging of high-speed 
camera. In this work, the recording frame ratios of high-speed camera was set to $11,000 \mathrm{fps}$. For all tests, the settings of high-speed camera kept the same.

A synchronizer was used to trigger the laser and high-speed camera. The heating expansion, melting, gasification, ignition delay time, and burnout time of $\mathrm{Mg}$ microparticles were determined using the time interval between laser onset and each representative stages occurrence recorded by high-speed camera.

\subsection{Experimental Procedures}

In the experiments, $\mathrm{Mg}$ microparticles were firstly dried in an oven at $120^{\circ} \mathrm{C}$ for about $1 \mathrm{~h}$. Then, $\mathrm{Mg}$ microparticles were fetched to cool to room temperature. Finally, $\mathrm{Mg}$ microparticles were delivered by the spoon controlled by manual vibration into the open combustor installed on a sample stage with 3-axis (X, Y, and Z) translation, and were sparsely distributed on the bottom of the combustion chamber. $\mathrm{Mg}$ microparticles were exposed into the air with natural convection at room temperature $\left(25^{\circ} \mathrm{C}\right)$, atmospheric pressure (1 atm) and relative humidity (39\%).

In this work, 60 individual Mg microparticle samples were selected to conduct the laser ignition experiments. The detailed particle diameters were measured by the microscopy, their size distribution was shown in Figure 6. It demonstrates that the diameter of $\mathrm{Mg}$ microparticles ranged from 19 to $80 \mu \mathrm{m}$, and most of $\mathrm{Mg}$ microparticles were $45-75 \mu \mathrm{m}$.

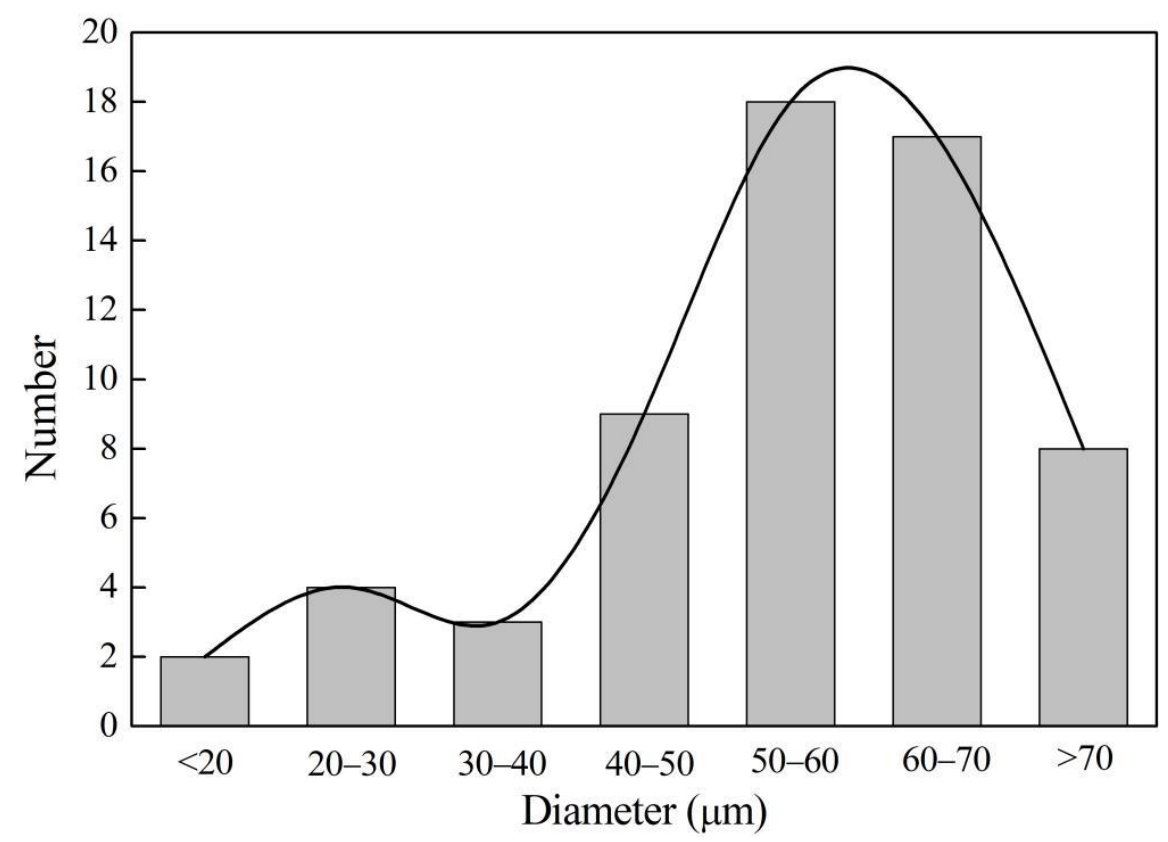

Figure 6. Particle diameter distribution of 60 individual $\mathrm{Mg}$ microparticles.

The 3-axis translation platform was adjusted to keep an isolated individual Mg microparticle appear in the field of vision of the high-speed camera. It was to eliminate the influence of other $\mathrm{Mg}$ microparticles on the present $\mathrm{Mg}$ microparticle. Then, $\mathrm{Mg}$ microparticle was moved by 3-axis translation platform and positioned under the laser beam. The laser and the high-speed camera were synchronously triggered. The ignition and combustion of individual $\mathrm{Mg}$ particles could be clearly observed through the high-speed camera at high temporal and spatial resolutions.

The ignition and combustion behavior of $\mathrm{Mg}$ microparticles depends on the laser power density and particle size, thus the effects of the $\mathrm{Mg}$ particle diameter and the ignition power density on the ignition delay time and the combustion time were also investigated by analyzing the images recorded by high-speed camera. The combustion residues were finally sampled and tested. 


\section{Results and Discussion}

\subsection{Combustion Stages of Individual Mg Microparticles}

By observing the whole combustion processes of tens of individual $\mathrm{Mg}$ microparticle samples, it can be found that, under the continuous action of laser, these combustion processes could be divided into four stages: expansion stage with migration, melting stage, gasification stage, ignition, and combustion stage. In this work, Supplementary Material Video S1 was set an example to analyze the combustion process, which demonstrated the combustion of an individual $\mathrm{Mg}$ microparticle (initial diameter of $64.8 \mu \mathrm{m}$ ) induced by a $\mathrm{CW}$ laser with an ignition power density of $0.96 \times 10^{5} \mathrm{~W} / \mathrm{cm}^{2}$.

After a short heating time, the individual $\mathrm{Mg}$ microparticle firstly underwent a small degree of thermal expansion. During expansion, $\mathrm{Mg}$ microparticle took a migration owing to the photophoretic force resulting from uneven temperature distribution at two sides of microparticle along the laser propagation direction [17,18]. As Mg microparticle was consistently heated by the laser till melting temperature $\left(648^{\circ} \mathrm{C}\right)$, it began to deform due to melting. The microparticle with high sphericity became irregular, and the melting stage lasted for a long time. Before the particle completely melted, it is considered that there was no gasification of $\mathrm{Mg}$. When the temperature continued to rise to the boiling point $\left(1107^{\circ} \mathrm{C}\right)$, molten $\mathrm{Mg}$ began to gasify. In the gasification stage, the vapor cloud can be clearly observed and quickly diffused. Finally, the gaseous Mg was heated till ignition temperature, and ignited by the laser. The flame brightness gradually intensified, resulting from gas phase combustion [19]. The evolution of combustion depended on the natural diffusion of $\mathrm{O}_{2}$ in air. The flame gradually extinguished and the whole combustion process completed.

To demonstrate more details of the whole combustion of the Mg microparticle, each stage was separately discussed in the following sections.

\subsubsection{Expansion with Migration}

The results show that the ignition of individual $\mathrm{Mg}$ microparticles can be induced by the continuous radiation of $1064 \mathrm{~nm}$ laser. The position of the laser spot remained unchanged, and the expansion and deviation did not make the $\mathrm{Mg}$ microparticle escape from the irradiation of laser spot, as shown in Figure 7. After the laser irradiated for $2.91 \mathrm{~ms}$, the position of the microparticle slightly shifted (Figure 7c), which is caused by the photophorestic force. Under the laser light field with high energy level, the microparticle absorbs or reflects light energy, which causes uneven energy distribution and temperature rise inside the particle. The gas molecules near the microparticle will also be heated, resulting in a temperature gradient, which leads to the unevenly heating of the local gas molecules, and thus makes the microparticle migrate irregularly. The similar migration phenomenon also occurred at $11.36 \mathrm{~ms}$ (Figure 7h), which is possible due to the temperature difference between two side of $\mathrm{Mg}$ microparticle. One side of the $\mathrm{Mg}$ microparticle was settled on a cold slide, while the other one was heated by the laser beam to keep a high temperature. The movement displacement was so small that the Mg microparticle still stood under the laser beam, and the $\mathrm{Mg}$ microparticle can be ignited by the laser beam. If the $\mathrm{Mg}$ microparticle escaped from the laser beam, the ignition would be stopped.

After the laser irradiated on the $\mathrm{Mg}$ microparticle for $5.82 \mathrm{~ms}$ (Figure 7d), a wisp of smoke was observed, which is attributed to $\mathrm{H}_{2}$ release by analyzing XRD pattern (Figure 2). Upon heating, the solubility of hydrogen in $\mathrm{Mg}$ will increase with the increase in temperature, and the hydrogen will be released [20]. However, the solubility trend is only valid for the interstitial solid solution of $\mathrm{H}$ in $\mathrm{Mg}$, and hydrogen may exist as a component of different phases, such as $\mathrm{Mg}(\mathrm{OH})_{2}$. Some researchers $[20,21]$ have shown that there is always $\mathrm{Mg}(\mathrm{OH})_{2}$ film on the surface of $\mathrm{Mg}$, and it begins to decompose at $350{ }^{\circ} \mathrm{C}$. The decomposition products of $\mathrm{Mg}(\mathrm{OH})_{2}$ are $\mathrm{MgO}$ and $\mathrm{H}_{2} \mathrm{O}$ below $420^{\circ} \mathrm{C}$, and $\mathrm{MgO}$ and $\mathrm{H}_{2}$ above $440^{\circ} \mathrm{C}$. Shevtsov et al. [22] also reported the existence of hydrogen in $\mathrm{Mg}$. At $6.73 \mathrm{~ms}$ (Figure 7e), the obvious expansion of the $\mathrm{Mg}$ microparticle was observed. The expansion ratio depended on the temperature rise. 


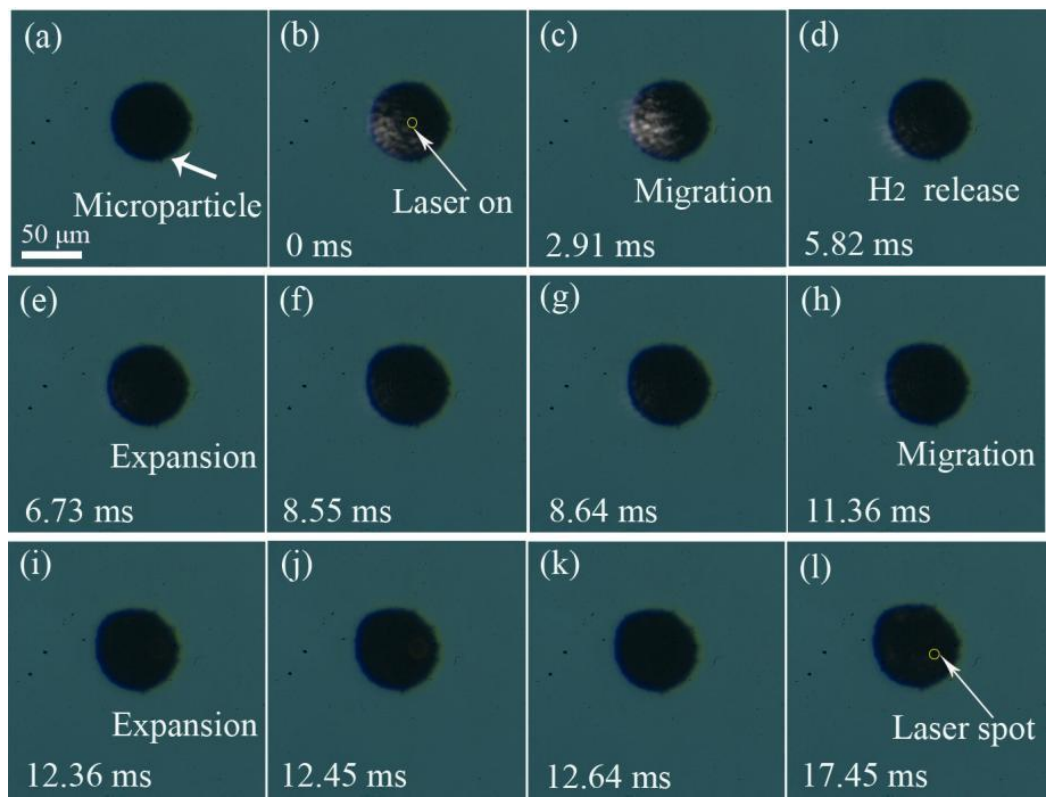

Figure 7. Representative snapshots of expansion and migration stage of individual Mg microparticle. (Images acquired from Supplementary Materials, Video S1, recording frame: 11,000 fps; exposure time: $99 \mu \mathrm{s}$ ). (a) Sample, (b) Laser on, $0 \mathrm{~ms}$, (c) $2.91 \mathrm{~ms}$, (d) $5.82 \mathrm{~ms}$, (e) $6.73 \mathrm{~ms}$, (f) $8.55 \mathrm{~ms}$, (g) $8.64 \mathrm{~ms}$, (h) $11.36 \mathrm{~ms}$, (i) $12.36 \mathrm{~ms},(\mathbf{j}) 12.45 \mathrm{~ms}$, (k) $12.64 \mathrm{~ms}$, (1) $17.45 \mathrm{~ms}$.

\subsubsection{Melting}

Figure 8 shows the melting process of the individual Mg microparticle. At $17.55 \mathrm{~ms}$, the shape of Mg microparticle became irregular. Dreizin et al. [19] believed that the release of hydrogen might lead to deformation and fracture of metal particles. Even in the absence of hydrogen, the expansion would also lead to the rupture of the oxide shell on the surface of Mg. Derevyaga [6] studied the combustion of a single millimeter-sized spherical Mg particle, and it was found that the expansion of particle led to the rupture of the surface oxide layer and the exposure of liquid $\mathrm{Mg}$. It suggests that the broken $\mathrm{Mg}$ particles reached the melting point temperature and began to melt. The partial solid phase Mg transformed into liquid phase $\mathrm{Mg}$ and outflowed the surface, so the shape of the microparticle became irregular. The whole melting process took a relatively long time $(\sim 93 \mathrm{~ms})$ and completed until $110.64 \mathrm{~ms}$ in Figure 8j.

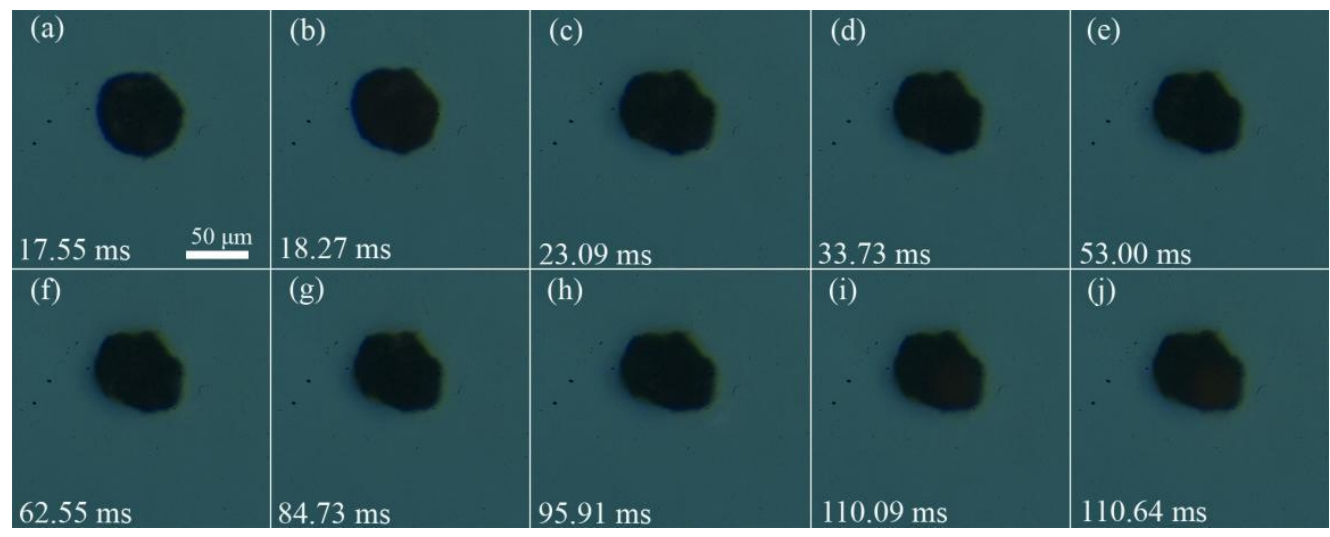

Figure 8. Representative snapshots of melting stage of individual Mg microparticle. (Images acquired from Supplementary Materials, Video S1, recording frame: 11,000 fps; exposure time: $99 \mu \mathrm{s}$ ). (a) 17.55, (b) $18.27 \mathrm{~ms}$, (c) $23.09 \mathrm{~ms}$, (d) $33.73 \mathrm{ms,}$ (e) $53.00 \mathrm{~ms}$, (f) $62.55 \mathrm{~ms}$, (g) $84.73 \mathrm{~ms}$, (h) $95.91 \mathrm{~ms}$, (i) $110.09 \mathrm{~ms}$, (j) $110.64 \mathrm{~ms}$. 


\subsubsection{Gasification}

When the laser continuously acted on the Mg microparticle for $110.73 \mathrm{~ms}$ shown in Figure $9 \mathrm{a}$, it can be found that a lot of gaseous matters released from the microparticle surface (see Supplementary Material Video S1 for details). It suggests that the molten Mg reached the boiling point and began to vaporize, and the gasification process gradually proceeded. At $117.36 \mathrm{~ms}$ in Figure $9 \mathrm{~g}$, the vaporized $\mathrm{Mg}$ appeared as a smoke cloud. Compared to the melting time ( $\sim 93 \mathrm{~ms})$, the gasification time $(\sim 7 \mathrm{~ms})$ was further shorter, indicating that the melting took a dominant role in the combustion process of the $\mathrm{Mg}$ microparticle.

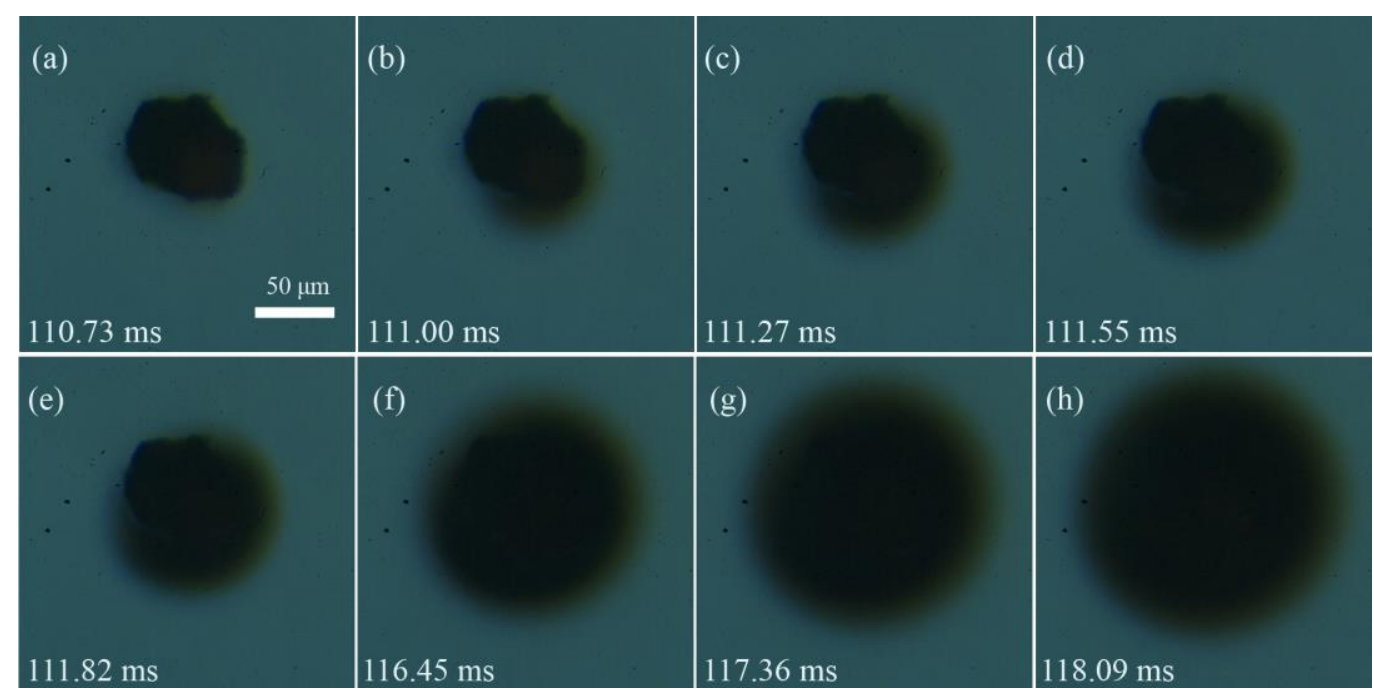

Figure 9. Representative snapshots of gasification stage of individual Mg microparticle. (Images acquired from Supplementary Materials, Video S1, recording frame: 11,000 fps; exposure time: $99 \mu \mathrm{s})$. (a) $110.73 \mathrm{~ms}$, (b) $111.00 \mathrm{~ms}$, (c) $111.27 \mathrm{ms,}$ (d) $111.55 \mathrm{~ms}$, (e) $111.82 \mathrm{~ms}$, (f) $116.45 \mathrm{~ms}$, (g) $117.36 \mathrm{~ms}$, (h) $118.09 \mathrm{~ms}$.

\subsubsection{Ignition and Combustion}

The ignition and combustion process of the individual $\mathrm{Mg}$ microparticle is shown in Figure 10. The ignition position depended on the focal point of laser. In this case, the ignition delay time of the $\mathrm{Mg}$ microparticle of $64.75 \mu \mathrm{m}$ in air was $118.18 \mathrm{~ms}$ at a laser ignition power density of $0.96 \times 10^{5} \mathrm{~W} / \mathrm{cm}^{2}$. After ignition, the flame of the $\mathrm{Mg}$ microparticle appeared circle and homogeneous, and the initial diameter of flame front was $31.50 \mu \mathrm{m}$ at $118.27 \mathrm{~ms}$ (Figure 10b). Then, the flame front quickly propagated. At $119.45 \mathrm{~ms}$ (Figure 10f), the diameter of flame front increased to $50.10 \mu \mathrm{m}$. Thus, at the rate of natural diffusion of oxygen in air, the flame propagation velocity reached $\sim 15.8 \mathrm{~mm} / \mathrm{s}$. At the brightest moment of flame, the diameter of front was $52.08 \mu \mathrm{m}$, while the flame structure kept heterogeneous (Figure 10g). After that, the flame brightness gradually weakened and finally extinguished. The combustion time of gaseous phase $\mathrm{Mg}$ was $4.37 \mathrm{~ms}$. The total combustion time was $122.55 \mathrm{~ms}$.

It can be observed that the initial flame structure of the $\mathrm{Mg}$ microparticle after ignition seemed rings (Figure 10a-c). Among these pictures, Figure 10b was selected to analyze the flame structure for the best observation. In Figure 11a, the gray values along horizontal and vertical lines through the center of flame ring were extracted by self-programming digit imaging treatment method, as shown in Figure 11b,c, respectively. They clearly demonstrated that the brightness inside the flame was obviously lower than that of the flame edge, suggesting that the temperature of inner flame was lower than that of outer flame. The phenomenon kept good agreement with the flame structure studied by Legrand et al. [13], which revealed that the $\mathrm{Mg}$ microparticles take gas phase combustion despite in air, in $\mathrm{H}_{2} \mathrm{O}$ or in $\mathrm{CO}_{2}$, and the flame structure or the reaction zone is relatively thick. 


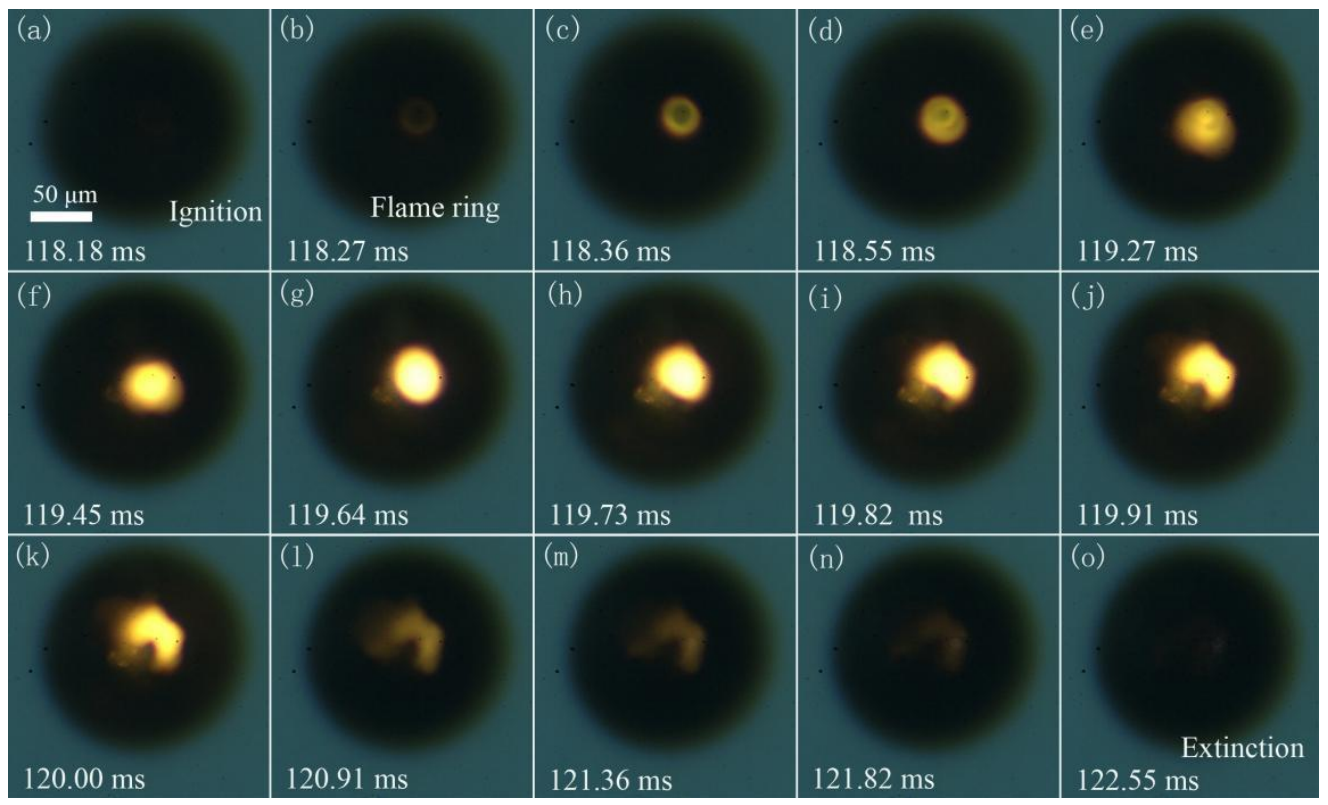

Figure 10. Representative snapshots of ignition and combustion stage of individual Mg microparticle. (Images acquired from Supplementary Materials, Video S1, recording frame: 11,000 fps; exposure time: $99 \mu \mathrm{s}$ ). (a) 118.18 , (b) $118.27 \mathrm{~ms}$, (c) $118.36 \mathrm{~ms}$, (d) $118.55 \mathrm{~ms}$, (e) $119.27 \mathrm{~ms}$, (f) $119.45 \mathrm{~ms}$, (g) $119.64 \mathrm{~ms}$, (h) $119.73 \mathrm{~ms}$, (i) $119.82 \mathrm{~ms}$, (j) $119.91 \mathrm{~ms}$, (k) $120.00 \mathrm{~ms}$, (l) $120.91 \mathrm{~ms}$, (m) $121.36 \mathrm{~ms}$, (n) $121.82 \mathrm{~ms}$, (o) $122.55 \mathrm{~ms}$.
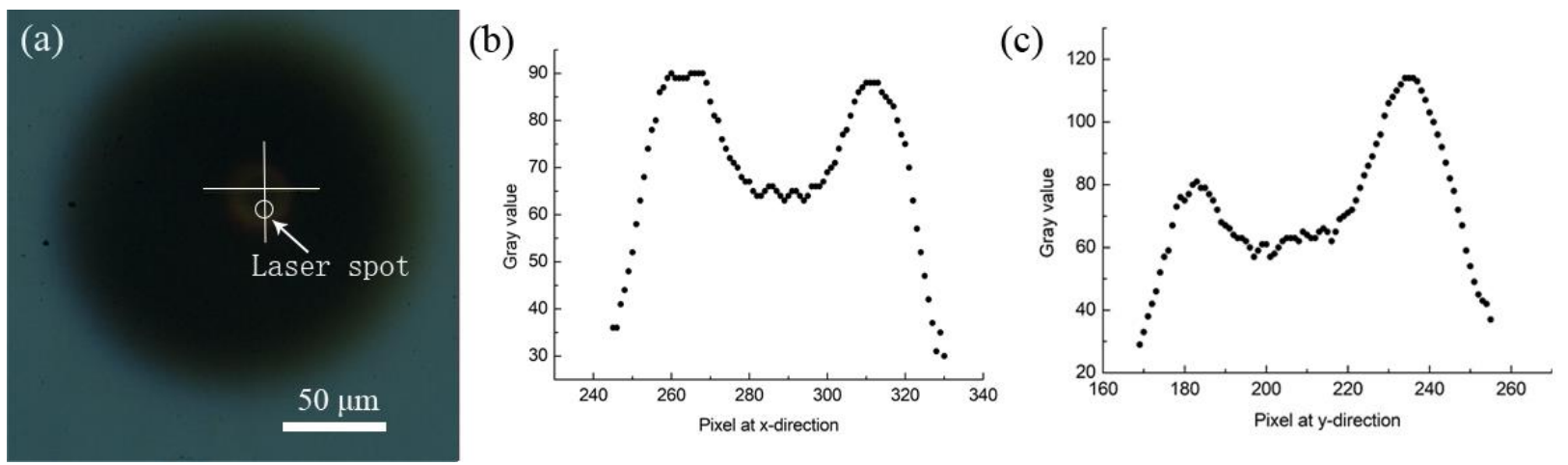

Figure 11. Flame structure of individual $\mathrm{Mg}$ microparticle, (a) flame picture at $118.27 \mathrm{~ms}$ (Figure $10 \mathrm{~b}$ ), (b) gray values along central horizonal line, (c) gray values along central vertical line inside the flame ring structure.

From Figure 10f-h, the flame structure took a significant transformation. The transformation of flame structure can also be observed from the images of other burning $\mathrm{Mg}$ microparticles, as shown in the region remarked by dotted oval of Figure 12. 

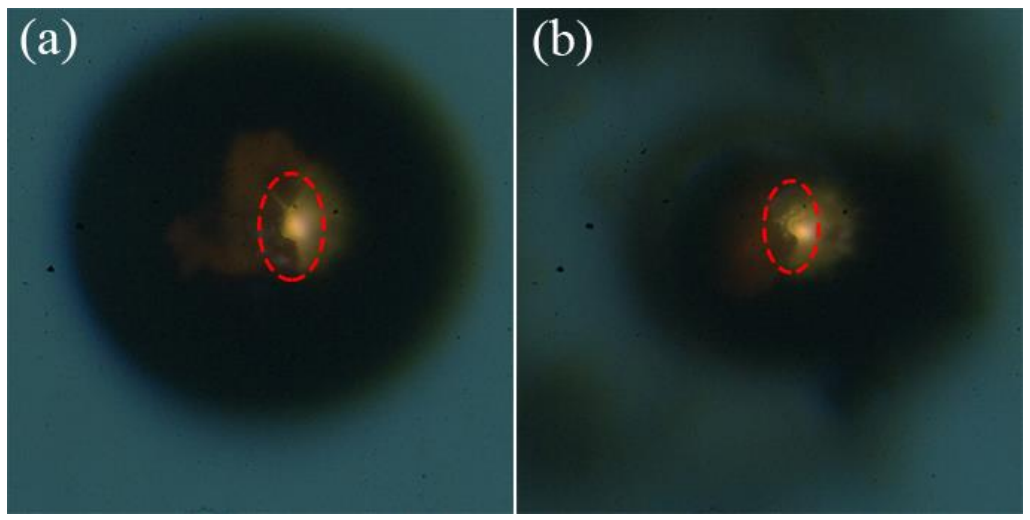

Figure 12. The transformation of flame structure during the combustion of individual $\mathrm{Mg}$ microparticle. (a) Flame structure before transformation, (b) Flame structure after transformation.

\subsection{Effect of Particle Diameter on Combustion Characteristics}

The ignition and combustion characteristics of individual $\mathrm{Mg}$ microparticles depend on the particle diameter and the ignition power density, as shown in Figures 13 and 14. The total combustion time was divided into two parts, i.e., the ignition delay time and gas phase combustion time after ignition. The ignition delay time played a significant role in the combustion evolution of individual Mg microparticles. In comparison to the ignition delay time, the gas phase combustion time was shorter. At the same ignition power density $\left(1.61 \times 10^{5} \mathrm{~W} / \mathrm{cm}^{2}\right)$, the ignition delay time and the total combustion time significantly increased with the increase in the particle diameter. The gas phase combustion time depended on the particle diameter and the diffusion rate of oxygen in air.

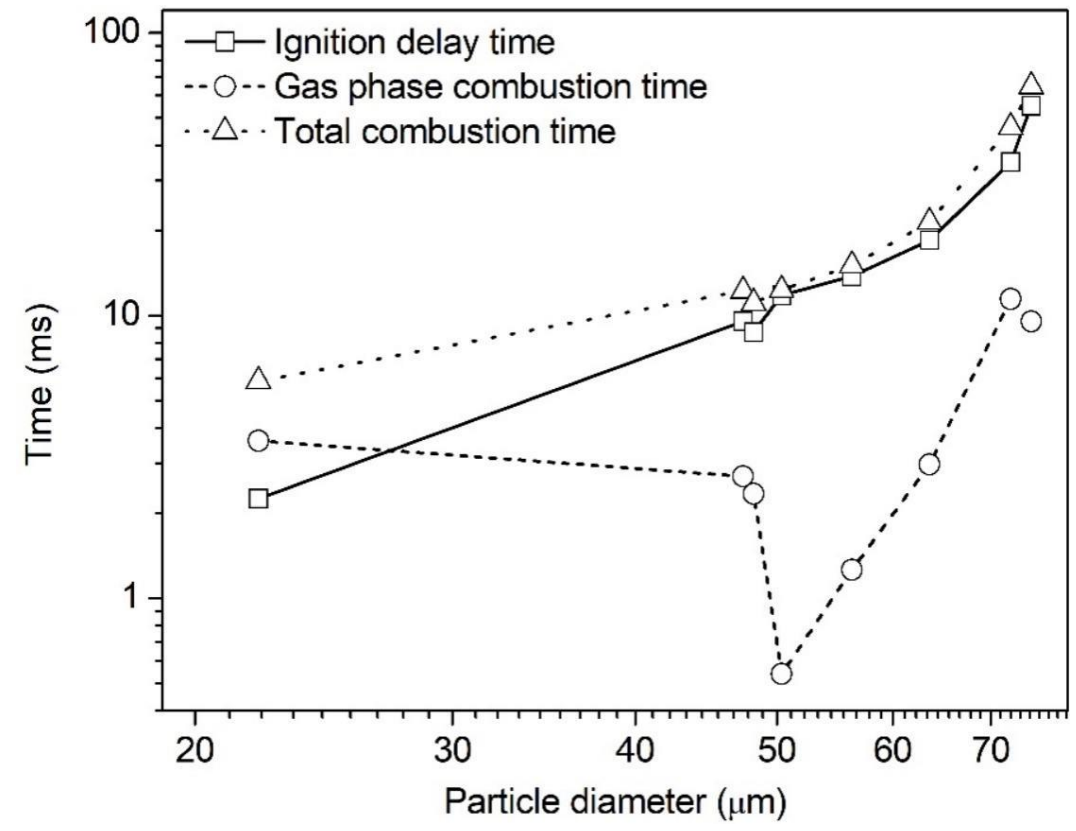

Figure 13. Characteristic ignition and combustion time of individual $\mathrm{Mg}$ microparticles at the same ignition power density $\left(1.61 \times 10^{5} \mathrm{~W} / \mathrm{cm}^{2}\right)$ against the particle diameter. 


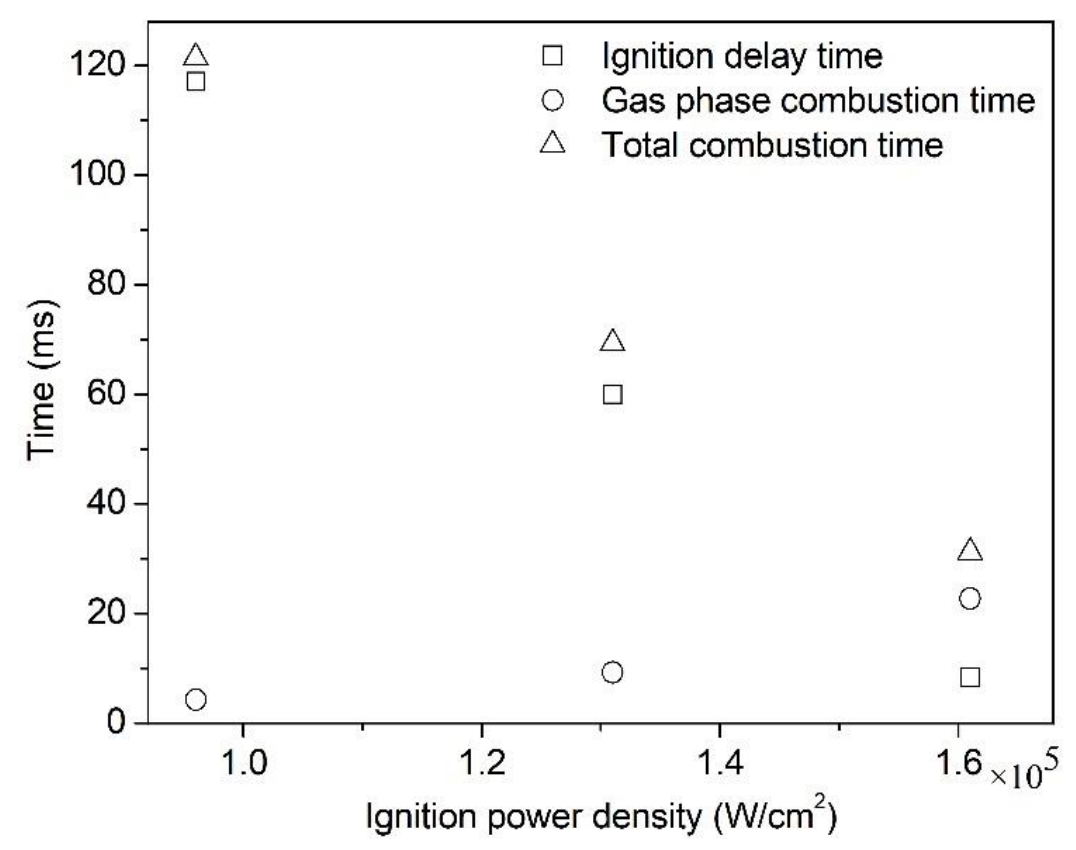

Figure 14. Characteristic ignition and combustion time of individual $\mathrm{Mg}$ microparticles at the same diameter $(\sim 65 \mu \mathrm{m})$ versus the laser ignition power density.

\subsection{Effect of Ignition Power Density on Combustion Characteristics}

Figure 14 shows that for individual Mg microparticles with the particle diameter of $\sim 65 \mu \mathrm{m}$, their ignition delay time and the total combustion time largely decreased with the increase in the laser ignition power density. To shorten the total combustion time of individual $\mathrm{Mg}$ microparticles, it should be feasible to lower the ignition delay time through increasing the ignition power density or through reducing the particle diameter.

According to the above combustion process, the energy equation of an individual $\mathrm{Mg}$ microparticle in each stage can be obtained.

In the heating stage, only the surface reaction of $\mathrm{Mg}$ microparticle is considered, the energy equation can be expressed as:

$$
m_{p} C_{p} \frac{d T_{p}}{d t}=\dot{Q}_{L}+\dot{Q}_{H S R}-\dot{Q}_{\text {loss }}
$$

where $m_{p}$ and $C_{p}$ are the mass and specific heat of the $\mathrm{Mg}$ microparticle, respectively. $\dot{Q}_{L}, \dot{Q}_{H S R}, \dot{Q}_{\text {loss }}$ are the laser ignition power, the release heat of heterogeneous oxidation reaction, and the heat loss containing the convection heat loss and the conduction loss to the chamber wall, respectively.

In the melting stage, only the surface reaction is considered, the temperature of the $\mathrm{Mg}$ microparticle remains at the melting point, and thus the energy equation can be written as:

$$
\dot{m}_{s l} h_{s l}=\dot{Q}_{L}+\dot{Q}_{H S R}-\dot{Q}_{l o s s}
$$

where $\dot{m}_{s l}$ and $h_{s l}$ are the melting rate and the latent heat of phase change, respectively.

In the combustion stage, the gas phase reaction and the surface reaction coexist, and the temperature of the $\mathrm{Mg}$ microparticle remains at the boiling point, and thus the energy equation can be considered as:

$$
m_{l g} h_{l g}=\dot{Q}_{L}+\dot{Q}_{H S R}+\dot{Q}_{R a d}-\dot{Q}_{l o s s}
$$

where $m_{l g}$ and $h_{l g}$ are the evaporating rate and latent heat of vaporization, respectively. $\dot{Q}_{R a d}$ is the radiation heat from the gas phase combustion. 
From the Equations (1)-(3), the increase in particle diameter results in the reduction in temperature rise rate, the melting rate and evaporating rate owing to the enhancement of particle mass $m_{p}$. It delayed the ignition time and made the total combustion time longer. The elevation of ignition power density is beneficial to accelerate the temperature rise, melting, and evaporating rate, which shortens the ignition delay and total combustion time.

\subsection{Combustion Residue Analysis}

The morphology of combustion residue of the $\mathrm{Mg}$ microparticle was characterized by SEM and is shown in Figure 15. It can be seen from Figure 15a that after the combustion of $\mathrm{Mg}$ microparticle, the residue was approximately circular, flat, and slightly embedded in the surface of the glass substrate. Figure $15 \mathrm{~b}$ shows the magnification of the local residue marked by dotted rectangle. The observation of the residue clearly shows that the morphology of the residue was not flying debris, while formed by solidification of falling oxides. The equivalent diameter of the range covered by combustion residue was about 2-3 times of the maximum cross-sectional diameter of the individual $\mathrm{Mg}$ microparticle before combustion. It is testified that the individual $\mathrm{Mg}$ microparticle took gas phase combustion.
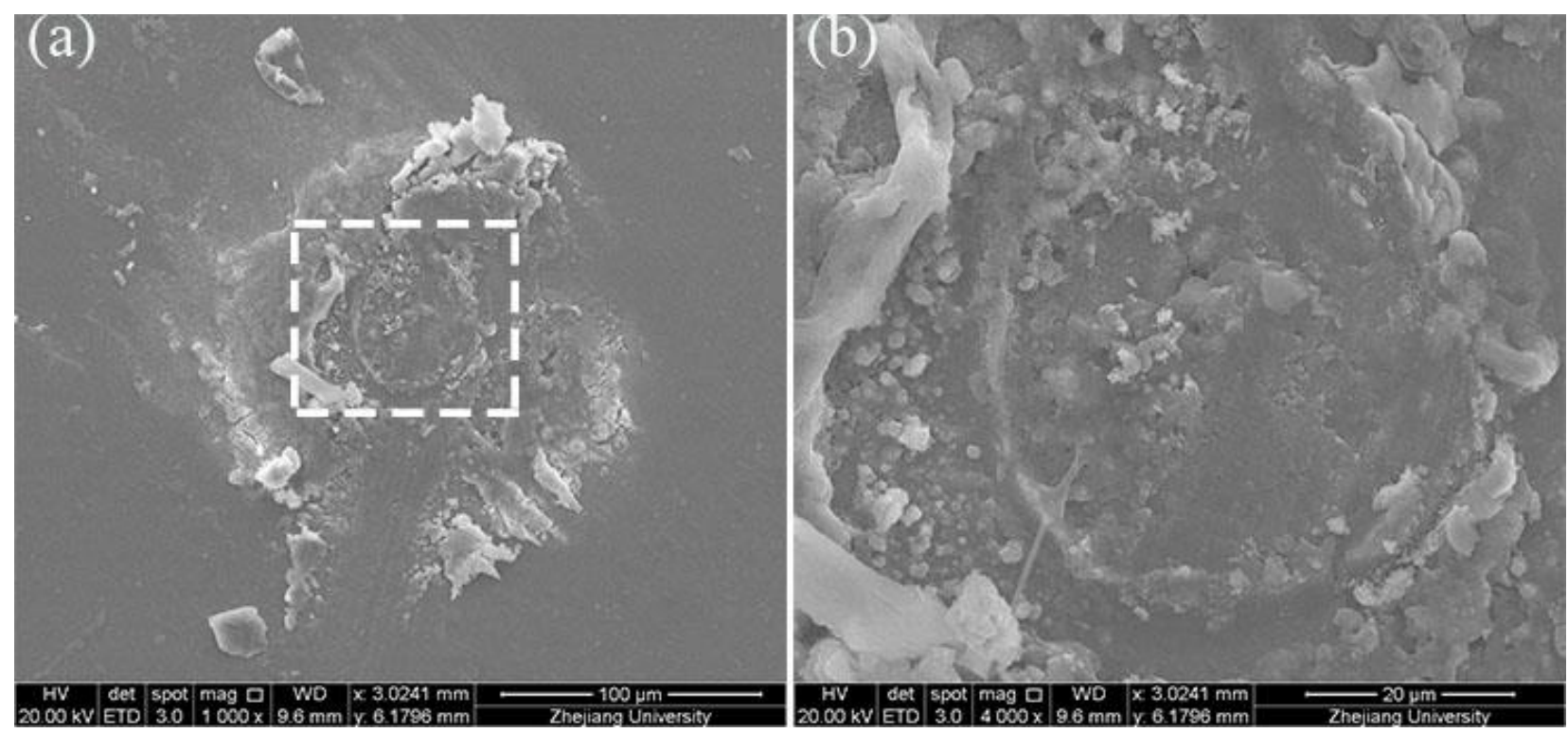

Figure 15. SEM photography of combustion residue of individual $\mathrm{Mg}$ microparticle, $(\mathbf{a})$ the whole residue $(1000 \times),(\mathbf{b})$ the local residue $(4000 \times)$.

The content of elements in combustion residue of the individual $\mathrm{Mg}$ microparticle was obtained by EDS analysis, as shown in Figure 16. It was found that the atomic percentage of $\mathrm{Mg}$ was $52.08 \%$, and that of $\mathrm{O}$ is $32.57 \%$. It indicates that $\mathrm{Mg}$ did not completely react with $\mathrm{O}$, since the atomic percentage of $\mathrm{MgO}$ is $1: 1$. In addition to $\mathrm{Mg}$ and $\mathrm{O}$ elements, there were also $\mathrm{Si}, \mathrm{Cl}, \mathrm{K}, \mathrm{Ca}$, and other elements, which indicates that the glass substrate of the combustion chamber had indeed melted and bonded with the combustion residue of Mg microparticle. 


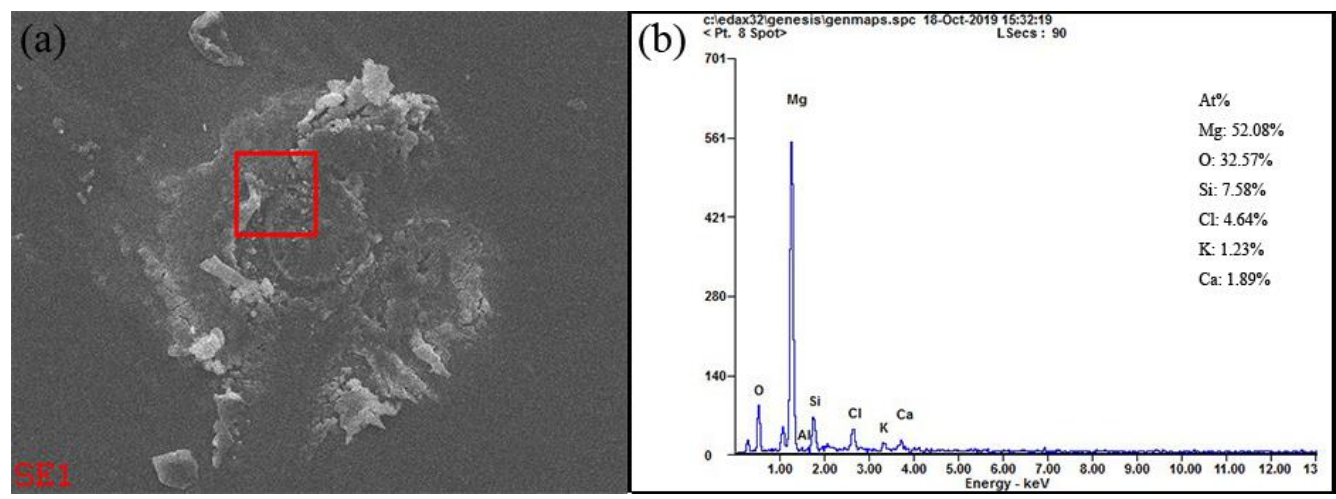

Figure 16. EDS spectrum of combustion residue of individual $\mathrm{Mg}$ microparticle, (a) The location of EDS analysis area in the residue (in the square box), (b) the content of elements, At \% represents the percentage of atomic number.

\subsection{Combustion Physical Model Analysis}

To accurately describe the actual reaction characteristics of Mg microparticles, many researchers have carried out many experimental and theoretical studies on the combustion characteristics of single $\mathrm{Mg}$ microparticles. Based on the combustion theory of hydrocarbon fuel droplets, Brzustowski et al. [23] established a simplified rapid reaction model of $\mathrm{Mg}$ particles. It was assumed that the reaction process is controlled by diffusion, and the gas phase composition depends on the equivalence ratio. The fast reaction is completed in "thin surface area" and the reaction rate is infinitely fast. However, it was found by Edward [19] that the reaction rate of $\mathrm{Mg}$ on the surface is not infinite. In this work, the reaction zone demonstrated thick characteristics.

Combined with experimental phenomenon and theoretical research of $\mathrm{Mg}$ combustion, the combustion reaction model of an individual $\mathrm{Mg}$ microparticle is shown in Figure 17. As the $\mathrm{Mg}$ microparticle is heated by the laser, the temperature of microparticle surface quickly increases. The $\mathrm{Mg}$ expands (Figure 7) and takes solid state reaction with $\mathrm{O}_{2}$ in air. With the increase in temperature, inside the microparticle, $\mathrm{Mg}$ melts from solid phase to liquid phase (Figure 8), and the temperature keeps constant. During melting, the $\mathrm{O}_{2}$ dissolves the liquid state $\mathrm{Mg}$ and takes liquid phase reaction. After completely melting, the temperature continues to rise. Liquid phase $\mathrm{Mg}$ begins to evaporate and transforms into gaseous $\mathrm{Mg}$ vapor (Figure 9). Evaporated $\mathrm{Mg}$ takes a gas phase reaction with the diffusive $\mathrm{O}_{2}$. As the heat released owing to exothermic reaction surpasses the heat loss to the air, the $\mathrm{Mg}$ vapor is ignited and takes a gas phase combustion (Figure 10). During combustion, the reaction zone $\delta$ is large, leading to a relatively wide flame thickness (Figure 11).

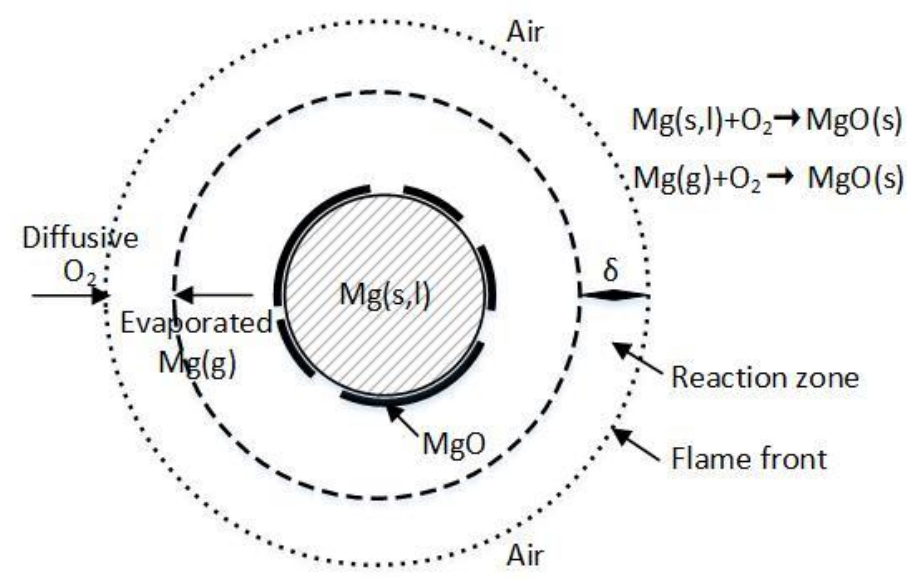

Figure 17. Schematic of physical model of individual Mg microparticle combustion. 


\section{Conclusions}

The experiments on combustion of individual $\mathrm{Mg}$ microparticles were conducted in the self-built experimental setup that combines the laser ignition with the microscopic highspeed cinematography. Based on the results and theoretical analysis, some conclusions can be reached as following:

1. The combustion process of individual $\mathrm{Mg}$ microparticles including four stages, i.e., expansion with migration, melting, gasification, ignition, and combustion, can be directly and clearly identified. The melting time is further longer than the evaporation time and gas phase combustion time. The melting plays a key role in the whole combustion process;

2. After individual $\mathrm{Mg}$ microparticles are ignited, initial outer flame presents the ring structure, unlike the reported thin flame layer with infinite fast reaction rate in the references, suggesting that the reaction zone or the flame thickness of $\mathrm{Mg}$ vapor in naturally diffusive air is wide;

3. The particle diameter and the ignition power density have significant effects on the ignition delay and combustion time. The ignition delay time shortens with the decrease in the particle diameter and the increase in the laser ignition power density. Since the gas phase combustion time is very short, the ignition delay time dominates the total combustion time.

This work will be beneficial to obtain the direct evidence through observing the complete combustion process of individual microparticles and to deeply understand the combustion mechanism.

Supplementary Materials: The following are available online at https:/ /www.mdpi.com/article/10 .3390/pr9081276/s1, Video S1: Supplementary material, video 1.

Author Contributions: Conceptualization, X.H., S.L. and J.X.; methodology, X.H.; investigation, C.L., M.Z., Y.W., S.L. and X.H.; data curation, C.L., M.Z., Y.W., S.L. and S.P.; writing-original draft, C.L., Y.W. and S.L.; writing - review and editing, S.L. and X.H. All authors have read and agreed to the published version of the manuscript.

Funding: This work was financially supported by the National Natural Science Foundation of China (51976050 and 41805108).

Institutional Review Board Statement: Not applicable.

Informed Consent Statement: Not applicable.

Data Availability Statement: There are any data need to be reported.

Conflicts of Interest: The authors declare no conflict of interest.

\section{References}

1. Yetter, R.A.; Risha, G.A.; Son, S.F. Metal particle combustion and nanotechnology. Proc. Combust. Inst. 2009, 32, 1819-1838. [CrossRef]

2. Dreizin, E.L. Phase changes in metal combustion. Prog. Energy Combust. Sci. 2000, 26, 57-78. [CrossRef]

3. Fathollahi, M.; Behnejad, H. A comparative study of thermal behaviors and kinetics analysis of the pyrotechnic compositions containing Mg and Al. J. Therm. Anal. Calorim. 2015, 120, 1483-1492. [CrossRef]

4. Li, L.B.; Chen, X.; Musa, O.; Zhou, C.S.; Zhu, M. The effect of pressure and oxygen concentration on the ignition and combustion of aluminum-magnesium fuel-rich propellant. Aerosp. Sci. Technol. 2018, 76, 394-401. [CrossRef]

5. Li, L.B.; Chen, X.; Zhou, C.S.; Zhu, M.; Musa, O. Experimental and numerical investigations of the effect of pressure and oxygen concentration on combustion characteristics of Al/Mg fuel-rich propellants. Appl. Therm. Eng. 2019, 167, 114695. [CrossRef]

6. Beckstead, M.W.; Puduppakkam, K.; Thakre, P.; Yang, V. Modeling of combustion and ignition of solid-propellant ingredients. Prog. Energy Combust. Sci. 2007, 33, 497-551. [CrossRef]

7. Cassel, H.M.; Liebman, I. Combustion of magnesium particles I. Combust. Flame 1962, 6, 153-156. [CrossRef]

8. Prachukho, V.P.; Ozerov, E.S.; Yurinov, A.A. Burning of magnesium particles in water vapor. Combust. Explos. Shock Waves 1971, 7, 232-236. [CrossRef]

9. Derevyaga, M.E.; Stesik, L.N.; Fedorin, E.A. Magnesium combustion regimes. Combust. Explos. Shock Waves 1978, 14, 559-564. [CrossRef] 
10. Shafirovich, E.Y.; Goldshleger, U.I. Ignition and burning of magnesium particles in caseous oxides of carbon. Combust. Explos. Shock Waves 1990, 26, 1-7. [CrossRef]

11. Shafirovich, E.Y.; Gol'dshleger, U.I. Combustion of magnesium particles in $\mathrm{CO}_{2} / \mathrm{CO}$ mixtures. Combust. Sci. Technol. 1992, 82, 33-43. [CrossRef]

12. Yuan, C.; Yu, L.; Li, C.; Li, G.; Zhong, S. Thermal analysis of magnesium reactions with nitrogen/oxygen gas mixtures. J. Hazard. Mater. 2013, 260, 707-714.

13. Legrand, B.; Marion, M.; Chauveau, C.; Gökalp, I.; Shafirovich, E. Ignition and Combustion of levitated magnesium and aluminum particles in carbon dioxide. Combust. Sci. Technol. 2001, 165, 151-174. [CrossRef]

14. Huang, X.; Yang, Y.; Hou, F.; Li, S.; Qin, Z.; Zhao, F. Laser-induced ignition and combustion of Al-Mg alloy powder prepared by melt atomization. Propellants Explos. Pyrotech. 2020, 45, 1645-1653. [CrossRef]

15. Pilling, N.B.; Bedworth, R.E. The Oxidation of Metals at High Temperatures. J. Inst. Met. 1923, 29, 529-591.

16. Hou, F.; Li, S.; Wang, Y.; Huang, X. Laser-induced ignition and combustion of individual aluminum particles below $10 \mu \mathrm{m}$ by microscopic high-speed cinematography. Processes 2020, 8, 280. [CrossRef]

17. Wurm, G.; Krauss, O. Experiments on negative photophoresis and application to the atmosphere. Atmos. Environ. 2008, 42, 2682-2690. [CrossRef]

18. Jovanovic, O. Photophoresis-light induced motion of particles suspended in gas. J. Quant. Spectrosc. Radiat. Transf. 2009, 110, 889-901. [CrossRef]

19. Edward, L.D.; Charles, H.B.; Edward, P.V. Condensed-phase modifications in magnesium particle combustion in air. Combust. Flame 2000, 122, 30-42.

20. Massalski, T.B.; Okamoto, H.; Subramanian, P.R.; Kacprzak, L. (Eds.) Binary Alloy Phase Diagrams; ASM International Publications: Materials Park, OH, USA, 1990.

21. Othmer, K. (Ed.) Kirk-Othmer Encyclopedia of Chemical Technology, 5th ed.; Wiley Interscience: New York, NY, USA, 2007; Volume 12 , p. 667.

22. Shevtsov, V.I.; Fursov, V.P.; Stesik, L.N. Mechanism for combustion of isolated magnesium particles. Combust. Explos. Shock Waves 1976, 12, 758-763. [CrossRef]

23. Brzustowski, T.A.; Glassman, I. Spectroscopic investigation of metal combustion. Prog. Astronaut. Rocket. 1964, 15, 41-73. 